\title{
A Field Trial on Mobile Crowdsourcing of News Content Factors Influencing Participation
}

\author{
Heli Väätäjä ${ }^{1}$, Esa Sirkkunen ${ }^{2}$, and Mari Ahvenainen ${ }^{1}$ \\ ${ }^{1}$ Tampere University of Technology, Korkeakoulunkatu 1, 33720 Tampere \\ heli.vaataja@tut.fi, mari.ahvenainen@tut.fi \\ ${ }^{2}$ University of Tampere, Kalevantie 4, 33100 Tampere \\ esa.sirkkunen@uta.fi
}

\begin{abstract}
We conducted a five-week field trial on mobile crowdsourcing of hyperlocal news content to 1) understand the readers' experiences and 2) explore factors affecting their participation. In the end of the study the participants were surveyed with an online questionnaire (17/104 respondents) and five participants were interviewed. Although respondents and interviewees were enthusiastic about the trial, the activity in the trial was low. Results indicate that participant characteristics (age, gender, participation motivations and hobbyist background in photography) and task characteristics in terms of the subjectively perceived task significance (possible impact on important issues in the environment or on community), task relevance (related to the background and participation motivation), and task engagingness have an effect on the participation. In addition, participation was influenced by the estimated needed effort vs. the expected benefit (monetary benefit or having a possibility to influence), vicinity to the assignment location, enjoyment of the activity, and the monetary reward. To plan and manage the crowdsourcing activity the news publishers need information about the characteristics of the participants, participation patterns and motivations that could be provided by the crowdsourcing platform.
\end{abstract}

Keywords: Crowdsourcing, user-generated content, hyperlocal, news, motivation, location, mobile, ubiquitous, reader, photo, Scoopshot.

\section{Introduction}

We have been witnessing a transformation of journalism as an industry and profession during the last ten years. It is evident that the old production models and professional cultures do not work in the age of digital, networked and socially shared media. A twofold process within the few last years has been taking place: User generated content (UGC) has been adapted more and more into news output and UGC creators have taken into account the editorial requirements of the newsrooms [1]. User-generated content (UGC) in this context refers to content that is created and contributed by nonprofessional reader reporters and reflects a certain amount of creative effort (adapted from [2]). So far UGC has been most often used in "soft and good news" when professional journalism is used in hard and bad news [3]. In case of eyewitness news on 
breaking topics, such as riots, disasters, and accidents, newsrooms have started to use social media as an important source of material [4-5].

There are especially rich possibilities to utilize UGC and crowdsourcing in the field of hyperlocal news, which are most often distributed free of charge to the readers in print or online. By hyperlocal news content we refer in this paper to content that pertains to a town, village, suburb, or other small, geographically defined community [6]. There are already numerous hyperlocal outlets for example in the UK which rely heavily on the readers' content, such as stories, photos and videos [6]. Especially hyperlocal newspapers collaborate with readers in content creation, because their editorial staff is few in number and the readers are well-informed of the hyperlocal, interesting and timely issues. Furthermore, other readers' material is considered trustworthy and authentic [1, 7-8].

One of the possibilities to get UGC for the hyperlocal news is mobile crowdsourcing. By mobile crowdsourcing we refer to a form of crowdsourcing, in which the initiator sends a task or makes available a task for voluntary undertaking by using mobile phones as an enabler for receiving or accessing the assignments and for submitting the news content (adapted from [9-10]). So far there is little prior research done concerning mobile crowdsourcing processes facilitated by news organizations publishing hyperlocal news, although the use of mobile assignments in news briefings have been reported [11]. This study addresses this gap. We report findings from a five week long field trial on crowdsourcing hyperlocal news content with a weekly mobile assignment. Findings are based on an online questionnaire (17/104 respondents) and interviews of five participants after the trial.

The goal of the research was to explore the characteristics of the participants and participation, as well as participants' experiences and identify the factors affecting participation. The goal for the news publisher was to use the findings in the development of their collaboration processes. In addition, the news publisher wanted to find out, whether young people could be activated to the collaboration by using a novel collaboration process and system. The main research questions were the following: How do participants experience the trial and the crowdsourcing solution? What factors affect the participation in the crowdsourcing activity? What implications are found for the development of the mobile crowdsourcing systems and processes?

To our knowledge, this is one of the first studies that reports on using mobile assignments for crowdsourcing in a real-world field trial carried out by a hyperlocal news organization. We present and discuss the findings on experiences and factors affecting participation and participation preferences. Based on the findings we provide implications for designing crowdsourcing processes and systems.

\section{Related Work}

Attitudes towards user-generated content (UGC) have changed during the last few years both on newsroom and reader reporters' side. Newsrooms and content creators have co-adapted their practices as newsrooms have created new processes for UGC and UGC creators have simultaneously learned the expectations of the newsroom [1]. 
Varying combinations of intrinsic and extrinsic motivations [13-14] are reported for reader participation in the context of news [15-17, 10]. In case of news related UGC there are differences in motivations to contribute depending on the addressees of shared content, the goal of sharing as well as the intended outlet of the submitted UGC [12]. The strongest reported motivations for contributors of stories at a German hyperlocal site myheimat are individually perceived creativeness, the fascination of publishing and the enjoyment of presenting one's own ideas to a larger public [12]. Respondents also report typical journalistic motivations, including balancing different perspectives and informing other people [12]. Similar motivations have been found for readers' photo content in case of hyperlocal news. In case of hyperlocal news, in which the submitter of a news photo gets a monetary incentive for a photo published in printed news, the top reported motivations are fun, an opportunity to get a monetary reward, sharing one's photos with others, and informing the wider public about local issues $[10,17]$.

Prior research reports on the following dimensions for users' participation and preferences in mobile crowdsourcing:

- context of use $[10,18,20]$ - time, location, vicinity to task location, parallel other tasks or activity, social situation, technology/infrastructure

- assignment properties [10, 18-19] - validity (including time criticality), incentives, estimated time or other effort (e.g. travel distance) for carrying out a task

- assignment type $[10,18,20]$ - photo, video, information acquisition, action (such as conducting an interview)

- patterns of planning and carrying out assignments $[18,20]-$ a priori planning

- mobile service(s) with features and functionalities [10, 18-19, 20] - reception or search of assignments (push, pull, location-based), submission of UGC

- use of location information [10, 18, 20] - geotagging, locating for assignments

- privacy issues [10]

- perceived risk, benefit and value of disclosing location information [10]

- organization type [10] - local or national news publisher

- incentives $[10,18]$

Based on earlier literature on location-based crowdsourcing, the most preferred assignment types are photo [10, 18, 20], information acquisition [18], and video tasks [10]. Time-critical tasks and tasks with no incentive are not interesting [18] and solution should be achievable in 10 minutes [18].

Patterns of solving tasks are related to location and temporal dimensions. Tasks are preferred to be solved close to home [18], downtown [10] and in close vicinity of the current location $[10,18]$. Tasks are searched for during breaks during the day at work or studies or while going home [18] and solved after work [18].

In location-based crowdsourcing - where tasks are related to a certain location and either searchable by location or at the location - searching for tasks that can be carried out in close vicinity of the home was preferred [18]. Map or augmented reality based solutions are accepted for planning of the activity [20]. If user's current location is used for sending assignments to the user, obfuscation of query for the user's location is preferred or using anonymous but precise locating [10]. 
We used these previously mentioned dimensions of participation preferences and findings in creating the questionnaire items and interview themes for this study.

\section{Methods}

\subsection{Setup of the Study}

The hyperlocal news publisher, Sanoma News, operating in Helsinki metropolitan area in Finland, trialed a crowdsourcing platform called Scoopshot. Scoopshot is offered by a third party that acts as an intermediary (marketplace) [21]. It enables registered users, solvers (scoopshooters), to submit photos and videos from smartphones to be sold for media companies (seekers) at the price set by the solver. Scoopshooters may also carry out tasks created by media companies and get rewarded for their accepted submissions. The incentive for simple tasks is usually at maximum two euros. Prior to the trial, the news publisher received reader's content sent as text messages (short comments), multimedia messages (photos), as well as via email and an online form (photos, stories and tip-offs).

\subsection{Participants}

104 participants were recruited with a website banner at the online news site (Omakaupunki.fi). The banner was visible to every third visitor of the website for two and a half days. In the end of the trial there were seventeen responses to the online questionnaire and five respondents were interviewed on a voluntary basis.

\subsection{Apparatus}

The participants used their own smartphones, either iPhone (9/17) or Android (8/17) during the trial. Those participants (3/17), who had not used Scoopshot prior to the trial, installed it to their smartphone when joining the trial. The rest joined the news publisher's community. Participants used Scoopshot mobile client for accessing the assignments, shooting photos and submitting user-generated photo content. The user interface of the Scoopshot mobile service client is illustrated in Figure 1.

At the time of the study the platform did not provide access to the information on the news publisher's community members, such as demographic information, activity logs other than actual UGC submitted by members in past three days, prior accomplishments of members etc. Contacting a member was only possible for current submitted UGC if the creator had allowed the phone number to be attached to the content. For professional photojournalists, the online platform enabled uploading of portfolios, creating automatically a profile based on accomplishments and their quality as well as being able to contact a specific person directly for undertaking a job. 

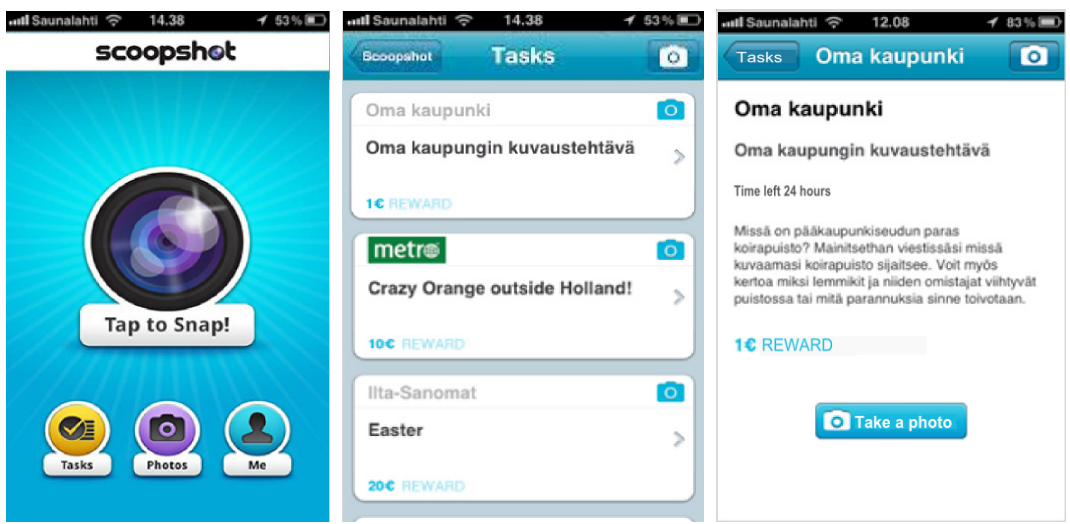

Fig. 1. Scoopshot mobile service client on iPhone. On the left, the opening page. In the middle the list of assignments. On the right an opened assignment.

\subsection{Assignments}

The participants were sent mobile photo assignments weekly, in total five (5) assignments (see Table 1) during March and April 2012. The editorial staff of the news publisher was responsible for planning of the assignments, sending them from the Scoopshot online portal, selecting the content to be purchased and publishing the content online and in the printed weekly news tabloid.

Table 1. Characteristics of the assignments and the activity during the trial $(\mathrm{N}=104)$

\begin{tabular}{|c|c|c|c|c|c|c|c|c|c|}
\hline \# & $\begin{array}{c}\text { Assignment } \\
\text { theme }\end{array}$ & $\begin{array}{c}\text { Validi- } \\
\text { ty }\end{array}$ & $\begin{array}{c}\text { Scoopshot } \\
\text { reward }\end{array}$ & Views & $\begin{array}{c}\text { Submit- } \\
\text { ters }\end{array}$ & $\begin{array}{c}\text { Phot } \\
\text { os } \\
\end{array}$ & $\begin{array}{c}\text { Purch } \\
\text { ased }\end{array}$ & $\begin{array}{c}\text { Prin } \\
\text { ted }\end{array}$ & Reward for print \\
\hline 1 & $\begin{array}{l}\text { Cleaning the } \\
\text { environment }\end{array}$ & $1 \mathrm{wk}$ & $1 €$ & 87 & 9 & 15 & 5 & 4 & $50 €$ \\
\hline 2 & Tallinn shipping & $12 \mathrm{~h}$ & $1 €$ & 68 & 2 & 27 & 2 & 1 & $50 €$ \\
\hline 3 & Noise barriers & $2 \mathrm{~d}$ & $1 €$ & 63 & 2 & 2 & 0 & 0 & - \\
\hline 4 & Best dog park & $2 \mathrm{~d}$ & $1 €$ & 64 & 2 & 2 & 2 & 1 & 2 movie tickets \\
\hline 5 & Street conditions & $1 \mathrm{~d}$ & $50 €$ & 56 & 3 & 7 & 1 & 1 & - \\
\hline
\end{tabular}

The most important properties for each photo assignment were a textual description of the photo assignment to be carried out, the validity of the assignment and the reward information. Scoopshot reward was paid for all bought photos. In addition, the participants were rewarded for photos published in print media. The recipient group in all the assignments was news publisher's own Scoopshot community. As an example, the description of the assignment on dog parks (\# 4) was the following:

"Where is the best dog park of the metropolitan area? Describe in your message where the dog park is located. You can also describe why pets and their owners enjoy the park or what improvements are wished for." 
The degree of activity decreased during the trial (Table 1). The first news assignment "Cleaning the environment", was viewed by 87 participants. The last news assignment of the trial was viewed by 56 of the participants.

Fourteen (14/104) participants sent photos to the news assignments. Most of them (10/104) submitted photos to only one assignment. The most popular assignment based on the number of submitters was the first assignment on "Cleaning the environment" with nine submitters. "Tallinn shipping" received the highest number of photos, but there were only two submitters and one of them submitted 26 photos. Purchased photos, were published online and most of the purchased photos were used in localized printed versions of the "Vartti" tabloid.

\subsection{Procedure}

Participants received a weekly mobile assignment via the Scoopshot mobile client. Answering to the assignments was voluntary. In the end of the trial the participants received as a mobile assignment an invitation to participate to the online questionnaire. The questionnaire was open online for two and a half weeks. There were 17 responses to the questionnaire and respondents were compensated with two movie tickets (value 18 euros). The themes covered perceptions of the trial and assignments, participation preferences and background information. Five respondents voluntereed to participate in a one hour interview. The five interviewees were compensated with two movie tickets. The semi-structured interviews were recorded and transcribed. In addition, log data of activity and generated content during the trial was collected.

\subsection{Analysis of the Data}

Questionnaire data was analyzed by descriptive statistics due to the small number of respondents. Interview data was analyzed by data-driven content analysis by identifying emerging themes in interviewees' perceptions and experiences.

\section{Results from the Online Questionnaire}

\subsection{Respondents' Background}

Demographics $(\mathbf{N}=\mathbf{1 7})$. Majority of the questionnaire respondents were male (16 male, 1 female). The youngest participant was 15 and eldest 53 years old $(M=28, S D$ $=10.4, \mathrm{Md}=26$ ). Eight respondents were aged between 15 and 25 indicating that this type of activity attracts younger age groups to participation as was hoped for by the publisher. We use a grouping to two age groups in the analysis, that is, 15-25 years and over 25 years. Results based on age group are presented when clear difference between the groups was found and it is relevant for the presentation of the results.

Education. The most common highest level of education was vocational degree (7/17). For the rest of the respondents the highest level of education varied from 
comprehensive school to a higher university degree. Six of the respondents were students, but otherwise the occupations varied.

Activity in Photo and Video Shooting. Respondents were active photographers. Over half of them reported taking photos daily (10/17) and the rest of them (7/17) weekly. The frequency of video recording was lower. Only one of the respondents recorded videos daily, and the rest of them weekly (8/17) or monthly and less frequently (8/17).

Prior Usage of Scoopshot. Scoopshot was the most often reported outlet for UGC that can be rewarded for. Most of the respondents (14/17) had used Scoopshot prior to the trial, primarily for carrying out other assignments than news assignments.

Prior Sending of Photos to Media for Publication. Twelve (12/17) respondents reported sending reader's photos prior to the trial. They were asked to report in more detail how often during the last half a year they had sent photos to 1) the hyperlocal news publisher, 2) other news media and 3) Scoopshot prior to the trial. For most participants the frequency to send reader's photos to hyperlocal news or other media was low prior to the trial - either monthly, less than monthly or never. One of the respondents was an active weekly contributor to all three output channels. Another respondent was an active daily user of Scoopshot.

\subsection{Assessment of the Trial and Scoopshot}

Overall Assessment of the Trial. The respondents were asked to describe the trial by completing a sentence with 1-3 different endings. The question was as follows: "How did you find the trial? Please, complete the sentence with one to three endings. In my opinion the trial was...". There were altogether 38 different sentence completions of which 32 were categorized as positive. Trial was assessed as interesting (9/38), novel $(8 / 38)$ and pleasant $(6 / 38)$. The negative comments were related to wishing for more tasks or a lower number of tasks than expected. Overall, twelve respondents (12/17) described the trial only positively, and the rest both positively and negatively.

Suitability of Scoopshot. Scoopshot was assessed as suitable for receiving assignments as well as for submitting photos. Sixteen respondents (16/17) rated suitability for receiving the assignments to be between 8 and 10 (11-point scale: $0=$ not suitable, $10=$ extremely suitable). For sending photos the rating for suitability was somewhat lower as twelve respondents (12/17) rated the suitability to be 8 or higher.

\subsection{Answering to the Assignments}

Age as a Determinant. The older respondents were more active contributors than age group 15-25 years. Ten (10/17) respondents reported that they had submitted photos to the assignments. Eight of them were aged over 25 years. Six respondents of the seven who did not submit photos were aged between 15 and 25 years. 
Reasons for Answering to the Assignments of the Trial. Those respondents who reported answering to the news assignments of the trial (10/17), were next asked a multiple choice question for their reasons to answer (Figure 2). Answering was motivated by an interesting assignment, enjoyment of activity when searching for a suitable subject to photograph and wanting to earn some money. Photography as a hobby, being close to a suitable location and easily finding a suitable topic to shoot the photo of were also mentioned. Other reasons mentioned in the open field were opportunity for influencing and gaining new experiences with technology.

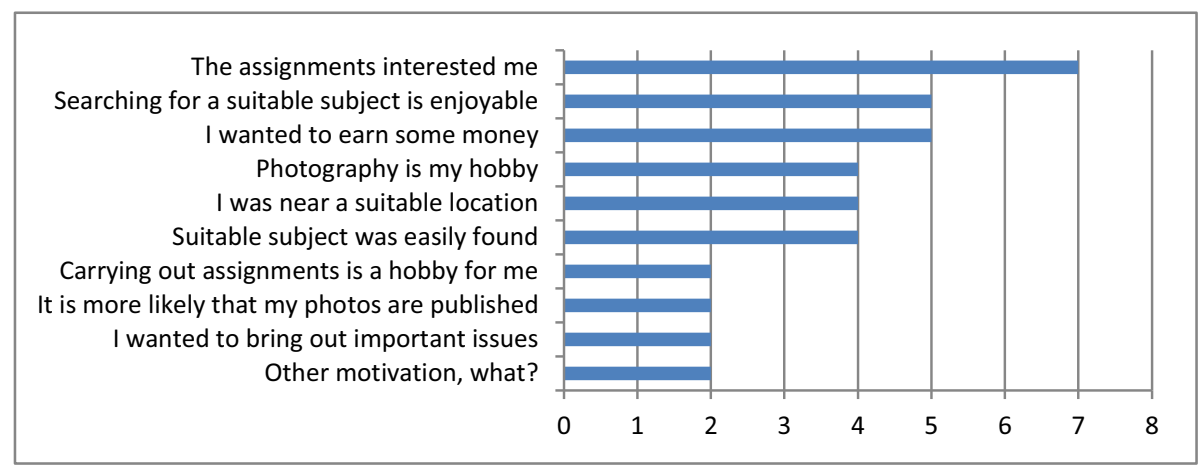

Fig. 2. Reasons for carrying out assignments $(\mathrm{N}=10)$

Reasons for Not Answering to the Assignments of the Trial. Those who did not answer to any of the news assignments in the trial (7/17) were asked for the reasons not to answer (Figure 3). Most often reported reasons for not carrying out assignments were that a suitable subject to shoot a photo was not found or the respondent was far from the location of the assignment. In addition, reason mentioned as "other" was related to the location, specifically, the respondent did not live in the area where the assignments were supposed to be carried out. Interestingly, none of the respondents reported as a reason for not answering the following options that were offered to them: "The assignments did not interest me", "I did not follow the offered tasks", and "I believe, that I will not get a reward".

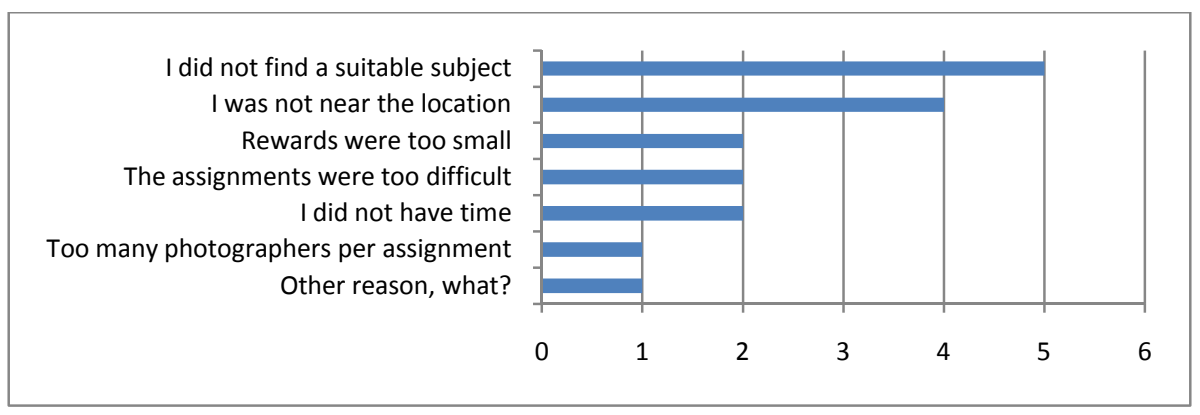

Fig. 3. Reasons for not carrying out assignments $(\mathrm{N}=7)$ 


\subsection{Assessment of the Assignment Themes}

Respondents were asked with a multiple choice question to assess the assignment themes in the trial. The question was asked in a form of sentence completion as follows: "The themes of the assignments were voluntary cleaning, Tallinn shipping, noise barriers, the best dog park and street conditions. What do you think about the themes? In my opinion the themes were...". We provided seven predefined attributes to be selected as the descriptive attributes and a possibility to choose "other" and to provide an open description for it (Figure 4).

To identify the predefined attributes (qualities) for this question, we asked nine externals (4 females, 5 males; age: 28 - 39 years) to describe with adjectives each of the five assignments of the trial. As an outcome 91 adjectives were collected. Adjectives with similar meaning were grouped and given a descriptive code. Seven most often reported attributes, with code counts varying from four to eight, were selected to be used in the questionnaire. This covered in total 44 of 91 original adjectives.

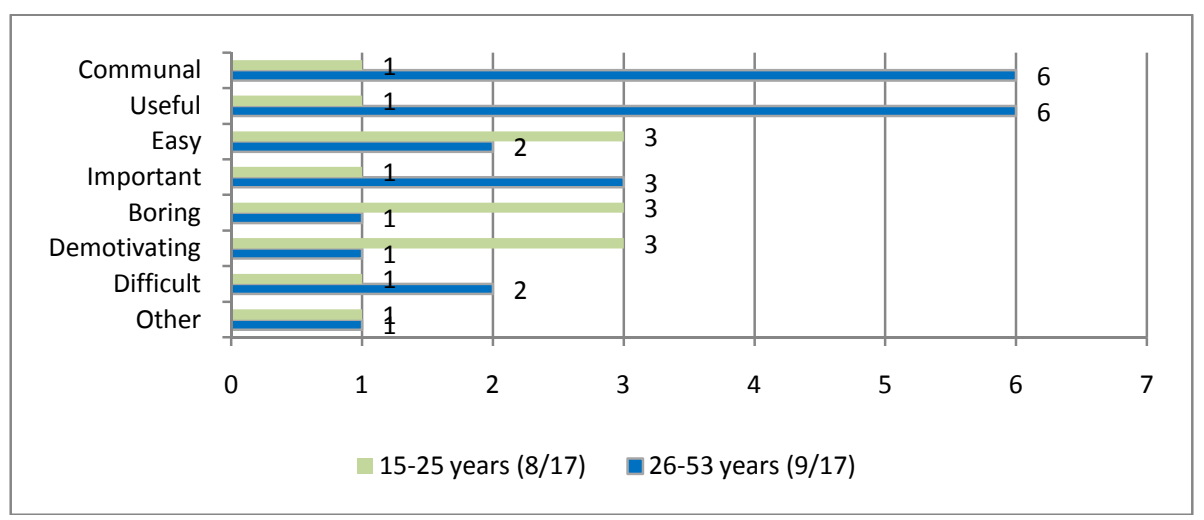

Fig. 4. Assessment of the assignment themes based on the age groups $(\mathrm{N}=17)$

Respondents assessed the themes as communal and useful, easy and important, but also boring and demotivating (see Figure 4). The young respondents (15-25 years), assessed the themes less positively than the older age group. Over half of the young respondents (5/8) assessed the themes as either boring or demotivating, whereas the older age group (over 25 years) assessed them communal and useful.

\subsection{Assessment of the Other Assignment Properties in the Trial}

Frequency of Assignments. Assignments in the trial were sent once a week. Respondents were asked "In your opinion, were the assignments sent often enough?" (Yes/No/I cannot say). Majority of the respondents (13/17) found that assignments were not sent often enough.

Suitable Length for Validity of the Assignments. The respondents were asked to rate the suitable length for validity of the sent Scoopshot assignments from four options: 1/2 day, 1 day, 2 days, and 1 week. A 5-point rating scale was used (too long, 
quite long, suitable, quite short, too short). The suitable length for the validity of an assignment was two days (14/17). Over half of the respondents (10/17) considered one day to be short and one week to be long. Half a day was considered to be short by all.

\subsection{Dimensions on Participation Preferences}

The respondents were asked with multiple choice questions preferences for assignment types, and on context related issues: in what situations, when and where they would prefer to carry out assignments $[10,22]$. They were also asked to estimate from given choices the maximum distance willing to travel for and the time willing to spend on an assignment.

Preferred Assignment Types. The respondents were asked what kind of assignments they would be interested in carrying out (see Figure 5). All respondents preferred photo assignments and over half of them also video assignments (11/17) and information acquisition (10/17), such as finding out how much a kilo of new potatoes costs on a market place. There was no difference between the age groups in the preferences.

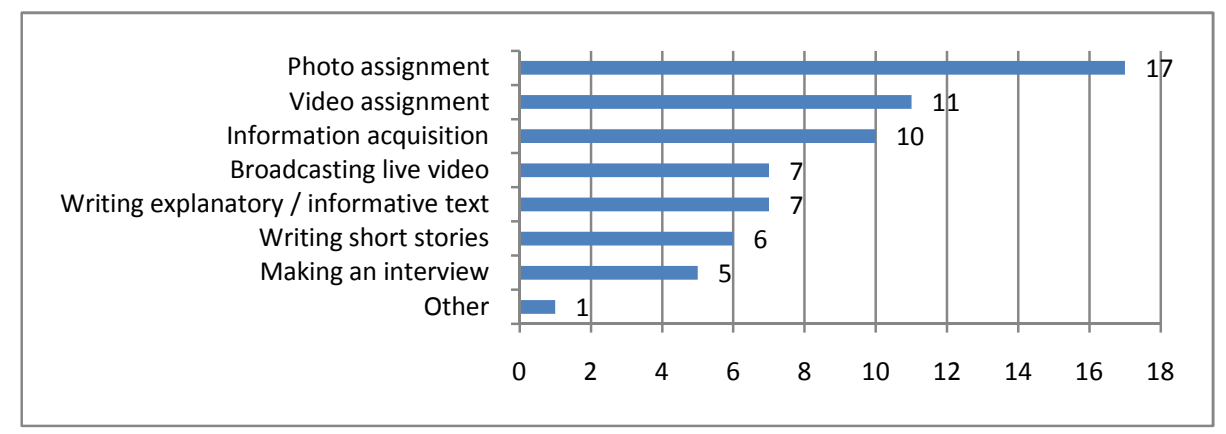

Fig. 5. Preference for carrying out different types of assignments $(\mathrm{N}=17)$

Preferred Situation (Task Context). Majority of respondents (15/17) were willing to carry out assignments on free time and over half of the respondents (11/17) when there is nothing else to do. Situations proposed by respondents in the open field were during hobbies and while waiting, i.e., when passing time.

Preferred Time (Temporal Context). Over half of the respondents (11/17) were willing to carry out assignments at any time. The most often reported specific times when willing to carry out assignments were weekends (8/17) and evenings (6/17).

Preferred Location and Vicinity (Spatial Context). All questionnaire respondents except one were willing to carry out assignments anywhere if they are in the vicinity of the assignment location (16/17) (Figure 6). Over half of the respondents (12/17) were willing to carry out tasks close to workplace, studies or near home. In addition, daily patterns of activities, such as commuting, generally during transitions between places and while shopping seem to be provide relevant times to carry out tasks. 


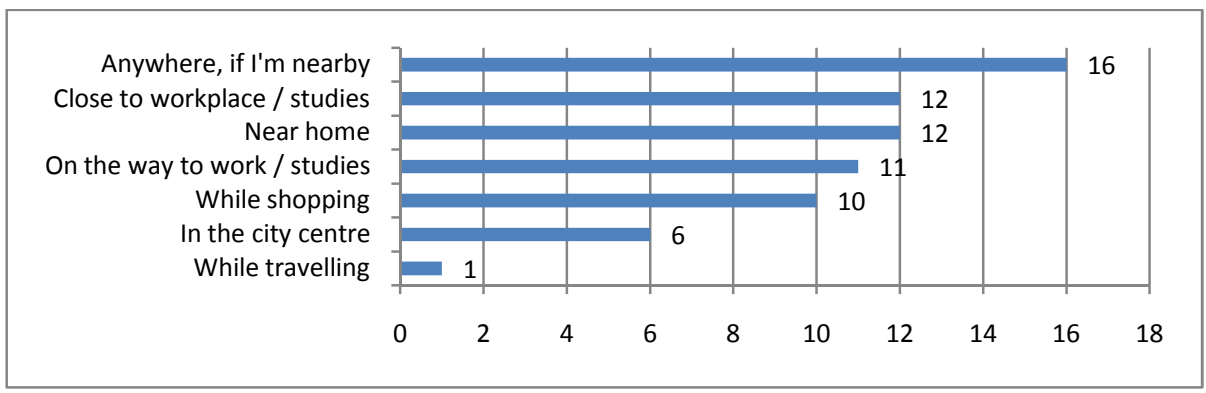

Fig. 6. Activities and locations to carry out assignments $(\mathrm{N}=17)$

Amount of Time Willing to Spend on an Assignment. Over half of the respondents (12/17) estimated willingness to spend even over a half an hour for carrying out an assignment, including the time for travel and submission (choices: 1-5 min, 10-30 min, less than an hour, more than an hour, other). However, this result may reflect more the maximum amount of time and be dependent on other factors, such as the interestingness of the assignment or the incentive.

Maximum Distance Willing to Travel for an Assignment. Choices given for estimating the maximum distance to travel were $1 / 2 / 5 / 10 / 15 /$ over 15 kilometers. Over half of the respondents $(9 / 17)$ were willing to travel at most five kilometers, whereas the rest reported willingness to travel even more than five kilometers.

\subsection{Positive Attitudes Contradict the Disappointment at the Trial}

In the end of the questionnaire the respondents were given a possibility to openly give feedback on the trial. Eleven respondents answered the question (11/17) giving twenty separate inputs. Four of the inputs were positive, ten negative and six neutral ideas and wishes. One of the respondents wished for continuation of the crowdsourcing activity, echoing the primarily positive assessments of the trial in the sentence completions reported earlier in subsection 4.3:

\section{"This felt like sensible activity. More of this!"}

Eight of the ten negative inputs were given by respondents who did not carry out assignments or who were aged between 15 and 25 years. Two of the negative inputs were related to the rewards, being either too small compared to the amount of work or to the required distance to travel. Some respondents also expressed to be disappointed with the trial, as they had high expectations in the beginning, but due to the assignment themes their enthusiasm faded. There were wishes for broader topics and that some topics would be more challenging than the others. Topics concerning the youth were wished for, reflecting the low participation activity by the young participants:

"More tasks concerning the young!! We are the future, hey? :P" 


\section{$5 \quad$ Results from the Interviews}

\subsection{Interviewees' Background}

Demographics. The five volunteer interviewees were male and their age was between 26 and $53(\mathrm{Md}=34)$ (Table 2).

Photographing. All interviewees had photography as a hobby. The primary motivations were intrinsic: they enjoy it because it is fun, creative and they constantly want to improve their skills. Three interviewees shot photos daily and two weekly (see Table 2). One interviewee found video shooting even more appealing than photographing and shared his videos in Youtube. Another one shared photos under Creative Commons license and his photos had been used for web publications, and magazines.

Prior Participation to News Making. One interviewee was an experienced contributor to news. He had started participation to news making almost 40 years ago by photographing and writing stories to the hyperlocal newspaper of his home town. The other interviewees had less participation experience to news making (see Table 2).

Table 2. Interviewees' background and characteristics

\begin{tabular}{|c|c|c|c|c|c|c|c|c|c|c|c|c|}
\hline \multirow[t]{2}{*}{$\begin{array}{l}\mathbf{A} \\
\mathbf{g} \\
\mathbf{e}\end{array}$} & \multirow[t]{2}{*}{$\begin{array}{l}\text { Photo- } \\
\text { graphing } \\
\text { as a } \\
\text { hobby }\end{array}$} & \multirow[t]{2}{*}{$\begin{array}{l}\text { Length of parti- } \\
\text { cipation to news } \\
\text { making }\end{array}$} & \multicolumn{3}{|c|}{$\begin{array}{l}\text { Created UGC } \\
\text { types to news: } \\
\text { Photo (P), } \\
\text { Video (V), } \\
\text { Story (S) }\end{array}$} & \multicolumn{2}{|c|}{$\begin{array}{l}\text { Preferred } \\
\text { mode: } \\
\text { Tasks (T), } \\
\text { Spontane- } \\
\text { ous (S) } \\
\end{array}$} & \multicolumn{2}{|c|}{$\begin{array}{l}\text { Intentio- } \\
\text { nal (I) vs. } \\
\text { Randomly } \\
\text { acting (R) }\end{array}$} & \multicolumn{3}{|c|}{$\begin{array}{l}\text { Channels } \\
\text { used: Web } \\
\text { form }(W), \\
\text { MMS (M), } \\
\text { Scoopshot (S) }\end{array}$} \\
\hline & & & $\mathbf{P}$ & $\mathbf{V}$ & $\mathbf{S}$ & $\mathbf{T}$ & $\mathbf{S}$ & I & $\mathbf{R}$ & $\mathbf{W}$ & $\mathbf{M}$ & $\mathbf{S}$ \\
\hline 26 & $>10$ years & 5 years & $\mathrm{x}$ & $\mathrm{x}$ & & $\mathrm{x}$ & $\mathrm{x}$ & & $\mathrm{x}$ & $\mathrm{x}$ & & $\mathrm{x}$ \\
\hline 28 & 2 years & A few years & $\mathrm{x}$ & & & $\mathrm{x}$ & & & $\mathrm{x}$ & & $\mathrm{x}$ & $\mathrm{x}$ \\
\hline 34 & $>10$ years & Since Scoopshot & $\mathrm{x}$ & & & $\mathrm{x}$ & & $\mathrm{x}$ & & & & $\mathrm{x}$ \\
\hline 38 & $>10$ years & Since the trial & $\mathrm{x}$ & & & $\mathrm{x}$ & & & $\mathrm{x}$ & & $\mathrm{x}$ & $\mathrm{x}$ \\
\hline 53 & 40 years & Almost 40 years & $\mathrm{x}$ & $\mathrm{x}$ & $\mathrm{x}$ & & $\mathrm{x}$ & $\mathrm{x}$ & & $\mathrm{x}$ & $\mathrm{x}$ & $\mathrm{x}$ \\
\hline
\end{tabular}

Photographing was a pleasing way to participate in news making for all interviewees (see Table 2). Two of them also sent video material. One interviewee submitted a lot of spontaneous photos and chose the outlet media based on the photo's topicality. Two interviewees can be characterized primarily as intentional and actively seeking photojournalists, whereas three are primarily randomly acting photojournalists [1516]. All interviewees were interested in carrying out assignments, although one of them preferred spontaneous photographing to tasks. He felt that by choosing the topics himself, he has more possibilities to influence.

\subsection{Perceptions and Development Ideas on Scoopshot}

Experiences with Scoopshot Prior to the Trial. Four interviewees liked the photo and assessment tasks of local companies that were initiated by a company providing 
directory services. One interviewee had carried out about one thousand tasks in one month. Another interviewee was not interested in simple tasks and hoped for themes with more challenge. Three interviewees had sold news photos via Scoopshot.

Suitability of Scoopshot. Scoopshot was found convenient, easy and effortless especially for assignment-based participation supporting the questionnaire findings. Moreover, it was found cost-effective as submitting is free of additional charge with a cellular data subscription or via a wireless network.

Ideas for Future Development. Some ideas for developing a mobile crowdsourcing platform arose in the interviews:

- Community like features: A possibility to see photos that other solvers have submitted to the assignments.

- Incentives: A possibility to submit news photos with no expected reward.

- Support for planning and carrying out tasks: Tasks available on a map view.

- Limiting the number of solvers: Assignments could be available to first five solvers close to the assignment location and if they are not able to submit sufficient content, the assignment would be opened to other solvers in the area.

- Support for using solvers with good reputation: An editor should be able to allocate an assignment to a reader reporter that is already known of one's good work. This calls for an implemented mechanism for reputation building.

Attitudes towards the Use of Location Information. Scoopshot uses the user's location information when accessing the tasks and it geotags the photos. Four of the five interviewees were positive towards the use of location information in news reporting reflecting the findings of earlier studies in this context [10, 20]. Four interviewees (4/5) found locating useful in general and they also used automatic geotagging of their photos. One interviewee described how geotagging provides added value for the viewers of the UGC by enabling location-based search for UGC and he therefore added the location information if it was missing. On the other hand, one interviewee explained how with some photos giving the exact location could be harmful, when photographing protected animals, for example. Instead of automatic geotagging, he added in these cases an approximate location to protect the source.

\subsection{Participation in the Trial}

Motivations to Participate in the Trial. The most common motivation to take part in the trial was interest in Scoopshot and assignments (4/5). One of the interviewees described, how he feels about receiving assignments and his participation:

“... always when I notice or the phone notifies when there is a new assignment, I check it. I find it fun. It makes one feel a bit important, or like own contribution really is somehow useful then. To me it gives pleasure. .. It is like playful, that you wait for an assignment to carry out and it feels really good." Male, 34

Carrying out assignments was described by the interviewees as fun, playful, and giving challenges and an opportunity to learn and experience something out of the 
ordinary. Interviewees also mentioned it to be a change to their own photographing and a pleasant additional activity. Interviewees also seemed to interweave the tasks to their everyday activities, such as when cycling to or from work, when walking a dog or when in transition between places during the work day as has been reported earlier for mobile gaming [23].

Feeling of Succeeding. A published photo or being able to influence with a photo gave a feeling of succeeding. Three of the interviewees felt that they had succeeded if their photos were published (3/5). One interviewee described how he had succeeded, if he himself was satisfied with the photo, whether the photo got published or not. For the interviewee with longest experience it was important to influence with his material and get something fixed, to repair a fault or to cause a change. He described:

"And I don't know, whether it creates contentment, that your own photo is in some newspaper, even that, you are used to it. But when you notice, as when I participated to the trial with assignment on potholes due to frost damage, when it [photo] was published in the newspaper, it was fixed within a week. It is, that it has influence. "Male, 53

In addition, the expressed interest by others towards their photo was a sign of succeeding. This interest could be the use of the photo for news, as a tip-off or idea for a news story, or someone wanting to use the photo for their other purposes. Furthermore, comments to their photo on the news site were a sign of success, showing that the photo raised interest.

Money as a Motivational Factor. Money and getting an incentive was not the most important motive to participate for the interviewees. However, the little extra income was a nice bonus and acknowledgement for the effort. None of the interviewees mentioned about the reward being too small, rather the other way around. One interviewee was willing to upload news photos to Scoopshot with no expected reward and another would carry out assignments even without any reward if the assignment was interesting enough. Altogether three interviewees expressed that they considered the possibility to influence and cause overall benefit with their photos more important than the reward. One of them commented the Cleaning the environment assignment as follows: "I think I got 50 euros from it. I was more satisfied, that it was cleaned up." Male, 53. The active background in photography and interviewee's participation motivations may influence the views on money and its role as an incentive.

Overall Assessment of the Trial. Interviewees found the trial interesting and fun and they were willing to continue participation. It was mentioned that having a clear assignment makes one think and approach it as a challenge to solve and that even competitive aspects came into play.

The most negative issues mentioned by participants were short the validity of assignments, the worn out and much used assignment topics and the impacts of reader participation. As negative impacts of reader participation two interviewees were worried about professional photographers' salary level being reduced or detracting from their jobs. One interviewee feared for the future impact on his work at the rescue services. He explained that if all reader reporters want to snap a photo of a fire, it will distract the rescue workers' operation on the scene of an accident 
Comparing Interview and Questionnaire Results. The most notable difference in interview and questionnaire responses is the distance willing to travel for an assignment (Table 3). In the questionnaire all interviewees were ready to travel five kilometers or more for an assignment, but in the interviews three of them preferred assignments on their way or needing to travel only a short distance. This could be the case also for other questionnaire respondents and similarly, the time willing to spend for carrying out tasks might be overestimated in the questionnaire results.

Table 3. Comparison of questionnaire responses and interviewees

\begin{tabular}{|c|c|c|c|}
\hline Topic & $\begin{array}{l}\text { Questionnaire } \\
\text { respondents }\end{array}$ & Interviews & $\begin{array}{l}\text { Interviewees in } \\
\text { questionnaire }\end{array}$ \\
\hline $\begin{array}{l}\text { Were the assignments } \\
\text { delivered often enough? }\end{array}$ & No $(13 / 17)$ & No $(5 / 5)$ & No $(4 / 5)$ \\
\hline $\begin{array}{l}\text { Assessment of assign- } \\
\text { ment topics (most imp.) }\end{array}$ & $\begin{array}{l}\text { Communal (7/17), } \\
\text { useful (7/17) }\end{array}$ & N/A & $\begin{array}{l}\text { Useful }(4 / 5) \text {, } \\
\text { communal }(3 / 5)\end{array}$ \\
\hline $\begin{array}{l}\text { Willingness to travel for } \\
\text { an assignment }\end{array}$ & $5 \mathrm{~km}$ or more $(14 / 17)$ & $\begin{array}{l}\text { On the way or short } \\
\text { distance }(3 / 5)\end{array}$ & $5 \mathrm{~km}$ or more $(5 / 5)$ \\
\hline $\begin{array}{l}\text { Suitable assignment } \\
\text { validity }\end{array}$ & 2 days $(14 / 17)$ & $\begin{array}{l}\text { Min } 1 \text {, max } 7 \text { days } \\
(5 / 5)\end{array}$ & $1-2$ days $(3 / 5)$ \\
\hline
\end{tabular}

\section{Discussion}

The field trial showed the importance of understanding the participant characteristics, perceived task characteristics, and participation preferences as factors influencing participation. Understanding these factors supports the planning and managing of mobile crowdsourcing activities within the context of hyperlocal news publishing, including the design of assignments and forms of participation. The crowdsourcing platform should support this understanding by providing information on the participant characteristics and participation patterns, as well as accumulate the collected knowledge and make it available for the newsroom. We next discuss the findings based on the trial and provide implications for designing crowdsourcing systems and processes, including assignment characteristics.

Perceptions on the Trial and Its Implementation. The questionnaire respondents were enthusiastic about the crowdsourcing activity and the trial with Scoopshot as the crowdsourcing platform. In the sentence completions the trial was described as interesting, novel and pleasant. Scoopshot was also assessed to be suitable for the mobile assignment based collaboration. However, the actual activity in the trial was low. The following reasons for this can be found in our findings.

First, the themes of the assignments were perceived positively as communal and useful primarily by the respondents from the older age group (over 25 years), whereas the younger age group (15-25 years) assessed the themes primarily as demotivating or boring. Interviewees described the themes as worn out and much used. The relevance of the themes to the participant groups as well as the engaging implementation of the 
participation needs to be paid attention to when planning the activity and assignment themes. In addition, the characteristics of the participant groups may vary depending on the channel chosen for reader participation and this should be taken into account in the planning of the activity and assignments.

Second, those respondents who answered to the assignments (10/17) reported as top reasons for carrying out the assignments the interestingness of the assignments (7/10), enjoyment of searching for a suitable subject to photograph $(5 / 10)$, and wanting to earn some money (5/10). The top reasons reported for not carrying out assignments (7/17) were not finding a suitable subject (5/7) and not being in the vicinity of the assignment or suitable location (4/7). In addition to the task relevance and engagingness of the assignments our results emphasize the enjoyment of the activity, monetary incentives and vicinity to a suitable location as important factors similarly to previous studies in mobile crowdsourcing [10, 17-18].

Third, the frequency of the assignments, which was in the trial one assignment per week, was found too low. Assignments were wished more frequently, with a preferred validity of two days, and several assignments were wished to be available at the same time to be able to pick from a set of assignments. This would allow more readers to participate and on the other hand enable choosing those of most interest.

Participation Preferences. Based on earlier research [10, 17-18]. we studied the following factors that influence participation preferences: 1) assignment types, 2) situations (task context), 3) time (temporal context), 4) location (spatial, i.e., physical context), and 5) effort needed in terms of a) time spent and b) distance travelled. Similar to previous studies photo assignments were the most preferred assignment type followed by video and information acquisition tasks [10, 18]. Respondents preferred carrying out assignments on free time and when nothing else to do, as reported previously [10, 18]. Furthermore, participants seem to interweave the assignments with their daily patterns of activities, such as when commuting or in transition to or from work, studies and home, when walking a dog or cycling, and while shopping. Similar findings have been reported previously for ubiquitous gaming [23] and in mobile crowdcourcing [18]. Augmented reality based solutions have been suggested for implementing support for readers when searching for tasks and planning own activity in hyperlocal news making [20]. Mobile client could provide support for making a plan and a route to follow, by being able to choose assignments to a task list and create a route or a map for oneself of the preferred assignments.

Although in this study the respondents were willing to carry out assignments at any time, the more specific reported times by the respondents, that is, weekends and evenings are similar to results reported in previous studies $[18,10]$. Questionnaire respondents were willing to carry out assignments if they were close the assignment location by, but specifically when close to workplace, studies or home. This indicates clearly the need for a possibility to search for assignments near the places relevant for the user as reported by Alt et al. [18].

We also studied the amount of effort willing to invest in the crowdsourcing activity, specifically in terms of 1) the time spent on an assignment including travel and submission, and 2) the distance travelled for the assignment. Questionnaire respondents reported willingness to invest relatively high effort in carrying out the tasks 
compared to earlier findings $[10,18]$. The results in our study on the willingness to put effort in carrying out the assignments therefore may be affected by other factors, such as the interestingness of the topic, the incentive and be valid only for a maximum effort willing to invest which may be affected by other factors as well. This seems to be the case based on the interview results, in which the vicinity to assignment location was emphasized. In addition, in the open comments of the questionnaire results the balance between the reward and the needed effort was brought up.

Motivations to Participate. The interviews of five participants with photography as a hobby revealed several motivations to participate in news making and crowdsourcing of news. These included the enjoyment of the activity and the variation it brings to their hobby, the opportunity to learn and experience something out of the ordinary, and the challenge and competition in solving the given assignment. Furthermore, the feeling of personal importance and value of one's contribution to the news making as well as the desire to influence something of interest to oneself were raised in the interviews. These motivations reflect the earlier findings on motivations to participate in news making $[12,16-17]$. The participation of the interviewees seems to be motivated primarily by intrinsic motivations, although the monetary reward was described as a little extra income that was a nice bonus for the effort invested.

For most of the interviewees the printed photo was an important feedback for success, giving satisfaction of one's accomplishment, as well as the comments on one's photo were a sign of success and a source of satisfaction. On the other hand, one of the interviewees emphasized how he was satisfied, when the photo had influenced the repairing of some issue rather than gaining a personal monetary benefit for the photo. This brings up the wider significance of own activity as an emerging theme. However, interview results are representative only for the special group of hobbyist photographers, who volunteered to be interviewed, rather than for a wider participating crowd.

The results from the questionnaire and interviews seem to indicate that the participant groups have different profiles in relation to the motivations and preferences to participate when mobile assignments are used. Some participants seem to take the tasks more seriously, almost as professional photojournalists, being critical about the quality of their work and wanting to improve their skills. Others seem to be motivated if the tasks touch issues that are important for them as citizens or residents of a certain area. The third group could be those that take part in order to earn some money or have fun, for example. Further studies in this area are therefore needed to support the planning of the crowdsourcing activities and collaborative news making.

Other Issues to Address in the Design of Crowdsourcing Systems and Processes. First, the newsroom needs to gain an understanding on different participant groups and their participation patterns and activity. This should be supported by the crowdsourcing platform or by other means. This calls for being able to collect, analyze and use collected information of the participants and submitted content to create knowledge on the participation. If an external crowdsourcing platform by a third party company is used, this company could provide the information as a service to the customer company. Second, the news publisher should provide multiple channels for participation to ensure participation independent of the socioeconomic background or 
technology savviness. To ensure equality and enable the readers to voice their views independent of their socioeconomic and demographic background, multiple channels of participation give possibilities for more diverse groups to participate and bring out issues important to them. Further issues that were suggested by participants to the developing the mobile crowdsourcing platform: a) community like features to support viewing of other users' content, b) a possibility to submit without any expected reward set as a price of the photo, c) limiting the number of solvers in the vicinity of the assignment location and d) creating a reputation system for the solvers that can be used by the newsroom staff to choose solvers with a good reputation to ensure the quality of the submissions.

Limitations and Future Research. Although the trial was limited in terms of the number of participants, its length and the number of sent assignments, the findings provide insights that can be taken into account when developing mobile crowdsourcing processes and enabling systems for it. There are several different paths to continue the research: participant characteristics, including socio-demographics and participation motivations in collaborative processes in news making, the use of incentives in this setting, developing the technological support, systems and processes for collaborative news making, ideating new enablers and participation forms for fun and playful experiences for participants, as well as further studies, experiments and trials in realworld on the factors affecting participation to enable successful use and management of crowdsourcing and to enable equal opportunities for readers to voice their views.

\section{Conclusions}

Findings indicate, that mobile crowdsourcing is a feasible option to be used in hyperlocal news making, that could 1) attract new participant groups to collaboration, 2) support a fun and playful way of participation, 3) give a possibility to influence, and 4) give an opportunity for little extra income. Results indicate that task characteristics in terms of the subjectively perceived significance (e.g. possible impact on important issues in the environment or on community), relevance (related to participant characteristics and participation motivation) and engagingness (fun and motivating) have an effect on the participation. Furthermore, participant characteristics, specifically age, gender, participation motivations and photography as a hobby seem to affect the participation. In addition, participation was influenced by the estimated needed effort vs. the expected benefit (monetary benefit or having a possibility to influence) the vicinity to the assignment location, enjoyment of the activity, and the monetary reward. Hobbyist background in photography seems to be connected to the interviewees' intrinsic participation motivations. As carrying out the tasks seems to interweave into daily activities, mobile user's activity should be supported by enabling the planning of the own participation activity by the crowdsourcing platform.

Crowdsourcing of photo content for news can be seen as a form of crowdsourcing of creativity [24]. Combined with a potential monetary reward the particular form of crowdsourcing studied in this trial combines the intrinsic and extrinsic participation motivations with varying emphasis depending on the participant characteristics. 
Our findings show, that it is important for the news publishers that the crowdsourcing processes and systems not only support the assignment related activity but also support understanding the motivations, participant characteristics as well as the underlying determinants and patterns of participation.

Acknowledgements. Special thanks to Tuukka Muhonen and the editorial staff at Sanoma News/Vartti for their cooperation in the study. This research was supported by TEKES as part of the Next Media programme of TIVIT and by the Finnish Doctoral Program on User-Centered Information Technology (UCIT).

\section{References}

1. Hänska-Ahy, M., Shapour, R.: Who's Reporting the Protests? Converging Practices of Citizen Journalists and Two BBC World Service Newsrooms, from Iran's Election Protests to the Arab uprisings. Journalism Studies 14(1), 29-45 (2013)

2. Wunsch-Vincent, S., Vickery, G.: Participative Web: User-Created Content [online document]. Organisation for Economic Co-operation and Development (OECD), Directorate for Science, Technology and Industry (2007), http: / / www. oecd.org/dataoecd/57/14/38393115.pdf

3. Paulussen, S., D'heer, E.: Using citizens for community journalism. Journalism Practice, 1-16 (2013)

4. Diakopoulos, N., De Choudhury, M., Naaman, M.: Finding and assessing social media information sources in the context of journalism. In: Proc. CHI 2012, pp. 2451-2460. ACM (2012)

5. Mortensen, M.: When citizen photojournalism sets the news agenda: Neda Agha Soltan as a Web 2.0 icon of post-election unrest in Iran. Global Media and Communication 7(1), 4$16(2011)$

6. Radcliffe, D.: Here and Now: UK hyperlocal media today. Nesta (2012),

http://www. nesta.org.uk/library/documents /

Here_and_Now_v17.pdf

7. Lai, S.: Iconic Images and Citizen Journalism. In: Proc. iConference 2011, pp. 702-703 (2011)

8. Wardle, C., Williams, A.: ugc@thebbc: Understanding its impact upon contributors, noncontributors and BBC News [online document], Cardiff, UK, Cardiff School of Journalism, Media and Cultural Studies, http: / / www .bbc.co.uk/blogs / knowledgeexchange/cardiffone.pdf

9. Estellés-Arolas, E., González-Ladrón-de-Guevara, F.: Towards an integrated crowdsourcing definition. Journal of Information Science 38(2), 189-200 (2012)

10. Väätäjä, H., Vainio, T., Sirkkunen, E.: Location-based crowdsourcing of hyperlocal news: dimensions of participation preferences. In: Proc. GROUP 2012, pp. 85-94. ACM (2012)

11. Väätäjä, H., Egglestone, P.: Briefing news reporting with mobile assignments: perceptions, needs and challenges. In: Proc. CSCW, pp. 485-494 (2012)

12. Fröhlich, R., Quiring, O., Engesser, S.: Between Idiosyncratic Self-Interests and Professional Standards: A Contribution to the Understanding of Participatory Journalism in Web 2.0. Results from an Online Survey in Germany. Journalism 1464884912442282 (2012)

13. Ryan, R., Deci, E.: Intrinsic and extrinsic motivations: Classic definitions and new directions. Contemporary Educational Psychology 25, 54-67 (2000) 
14. Nov, O., Naaman, M., Ye, C.: Analysis of participation in an online-photo-sharing community: A multidimensional perspective. J. of the Am. Society for Information Systems and Technology 61(3), 1-12 (2010)

15. Brabham, D.C.: Moving the crowd with iStockphoto: The composition of the crowd and motivations for participation in a crowdsourcing application. First Monday 13(6) (2008)

16. Buehner, T., Jones, J.: Exposing the digital newshound: A study of the values, influences, and characteristics of creators of citizen-journalistic photographic content. In: $2011 \mathrm{Mid}-$ winter Conference of the Association for Education in Journ. and Mass Communication (2011)

17. Väätäjä, H.: Readers' motivations to participate in hyperlocal news content creation. In: Proc. GROUP 2012, pp. 309-312. ACM (2012)

18. Alt, F., Shirazi, A.S., Schmidt, A., Kramer, U., Nawaz, Z.: Location-based crowdsourding - Extending crowdsourcing to the real world. In: Proc. NordiCHI 2010, pp. 13-22 (2010)

19. Väätäjä, H., Vainio, T., Sirkkunen, E., Salo, K.: Crowdsourced news reporting: supporting news content creation with mobile phones. In: Proc. MobileHCI 2011, pp. 435-444 (2011)

20. Väätäjä, H., Ahvenainen, M., Jaakola, M., Olsson, T.: Exploring Augmented Reality for User-Generated Hyperlocal News Content. In: CHI 2013 Extended Abstracts, Paris, France (2013)

21. Chesbrough, H.: Open business models - How to thrive in the new innovation landscape. Harvard Business School Press (2006)

22. Wigelius, H., Väätäjä, H.: Dimensions of context affecting user experience in mobile work. In: Gross, T., Gulliksen, J., Kotzé, P., Oestreicher, L., Palanque, P., Prates, R.O., Winckler, M. (eds.) INTERACT 2009. LNCS, vol. 5727, pp. 604-617. Springer, Heidelberg (2009)

23. Bell, M., et al.: Interweaving Mobile Games with Everyday Life. In: Proc. of CHI 2006, pp. 417-426 (2006)

24. Schenk, E., Guittard, C.: Towards a characterization of crowdsourcing practices. Journal of Innovation Economics 1(7), 93-107 (2011) 